01,07

\title{
Механизмы пластической деформации в нержавеющей стали в условиях высокоскоростного проникания компактных ударников
}

\author{
(C) С.А. Атрошенко ${ }^{1,3}$, А.Ю. Григорьев ${ }^{2}$, Г.Г. Савенков ${ }^{2}$ \\ ${ }^{1}$ Институт проблем машиноведения РАН, \\ Санкт-Петербург, Россия \\ ${ }^{2}$ Санкт-Петербургский государственный технологический институт (Технический университет), \\ Санкт-Петербург, Россия \\ ${ }^{3}$ Санкт-Петербургский государственный университет, \\ Санкт-Петербург, Россия \\ E-mail: satroshe@mail.ru
}

Поступила в Редакцию 7 мая 2019 г.

В окончательной редакции 7 мая 2019 г.

Принята к публикации 20 мая 2019 г.

\begin{abstract}
Представлены результаты исследования поведения аустенитной нержавеющей стали 08Х18Н10Т в условиях высокоскоростного проникания со скоростями $1.5-2.0 \mathrm{~km} / \mathrm{s}$. Показано, что в мишени при пробитии наблюдаются три зоны проникания, отличающиеся механизмами пластической деформации и разрушения.
\end{abstract}

Ключевые слова: Нержавеющая сталь, высокоскоростное проникание, механизмы пластической деформации.

DOI: 10.21883/FTT.2019.10.48242.476

\section{1. Введение}

Пробивание толстых преград компактными ударниками неправильной формы (КУНФ), например, типа ударного ядра [1], с начальными скоростями соударения $\sim 1.5-2.0 \mathrm{~km} / \mathrm{s}$ является, с точки зрения поведения материалов преград, наименее изученным явлением [2]. Отметим, что при таких скоростях удара в материале преграды реализуется диапазон скоростей деформации равный $10^{5}-10^{6} \mathrm{~s}^{-1}$, а исследование поведения материалов при таких скоростях деформации с помощью апробированных методик также наталкивается на ряд трудностей методического и измерительного характера.

В первую очередь это связано с тем, что при такой скорости удара в преграде развиваются большие пластические деформации, возникают различные дефектные структуры, разогрев материала становится существенным, что может привести в совокупности с высокими давлениями к фазовым и структурным превращениям. Однако при такой скорости удара поведение материала преграды в точке соударения еще не соответствует поведению идеальной сжимаемой жидкости, как это предполагается при скоростях соударения более $4.0 \mathrm{~km} / \mathrm{s}$ [3]. Кроме того, неправильная форма ударника приводит к сложному напряженно-деформированному состоянию, что также затрудняет анализ процессов, происходящих в толще материала преграды. В частности, неясной является эволюция структуры в процессе прохождения ударной волны, которая образуется при соударении ударника с преградой и бежит впереди ударника. Кроме того, затруднена оценка доли энергии, затраченной на формирование новых образовавшихся структур материала.

Естественно, что такое положение вещей затрудняет создание расчетных методов оценки прочности и несущей способности дорогостоящих конструкций (например, космических аппаратов (КА) при столкновении с метеоритными частицами и частицами космического мусора) при ударе с вышеназванными скоростями соударения. Поэтому для разработки адекватных моделей пробивания преград или внедрения (в случае преград полубесконечной толщины) необходим большой объем экспериментально-теоретической информации, характеризующий всю совокупность процессов, происходящих в преграде.

В то же время при исследовании процессов высокоскоростных взаимодействий частиц космического мусора с защитными экранами КА такие частицы имитируются сферическими ударниками различной массы [4], что, хотя и значительно упрощает обработку экспериментальных результатов и численное моделирование, приводит к значительной потери точности расчетов.

В настоящей работе были исследованы образцы, вырезанные из преград, пробитых КУНФ, описанных в работе [1]. Начальная скорость соударения составляла $\sim 1.8 \mathrm{~km} / \mathrm{s}$. Диаметр мишени - $90 \mathrm{~mm}$. Материал преграды - нержавеющая сталь 08X18Н10Т. Стандартные механические характеристики стали, полученные путем испытаний образцов по ГОСТ 1497, вырезанных из прутка, из которого изготавливались мишени, имели следующие значения: $\sigma_{0.2}=275 \mathrm{MPa}, \sigma_{B}=620 \mathrm{MPa}, \delta_{5}=59 \%$, $\psi=70 \%$.

\section{2. Образцы и методика исследований}

Общий вид образцов, подготовленных для металлографических исследований, представлен на рис. 1. Толщина образца - $11 \mathrm{~mm}$. 


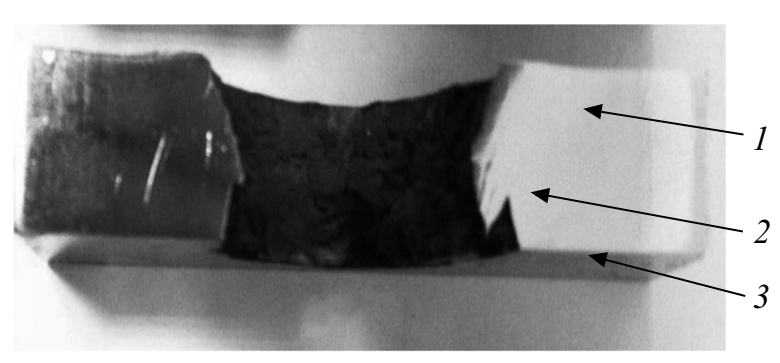

Рис. 1. Образец и зоны проникания.

Исходная структура стали 08Х18Н10Т представляет из себя неравноосные зерна размерами $150 \times 50 \mu \mathrm{m}$, в ряде мест разделены прослойками $\delta$-феррита. Морфология и ориентация зерен соответствует полигонизованному состоянию после горячей прокатки. Наибольшая ось зерен параллельна направлению движения ударника.

Исследования структуры проводились на оптическом микроскопе Axio-Observer Z1 M в светлом поле и в контрасте C-DIC.

Микротвердость стали определялась на микротвердомере SHIMADZU серии HMV-G (по методу Виккерса) при нагрузке $0.49 \mathrm{~N}$.

\section{3. Результаты металлографических исследований и их анализ}

В пробитой мишени выделяются три зоны проникания (рис. 1). Первая зона, обусловленная нестационарным этапом проникания [5], по глубине соответствует $\sim 0.5$ толщины пробития и, вторая $\sim 1 / 3$ толщины (стационарный этап проникания), третья (связана с откольными явлениями) $\sim 1 / 6$ толщины.

В первой зоне на расстоянии $1.5-3.8 \mathrm{~mm}$ от фронтальной поверхности и $0.15-0.75 \mathrm{~mm}$ от края каверны располагается область ротационной деформации, состоящая из дисков, имеющих, практически, идеальную форму окружности. Радиус дисков находится в диапазоне от 35 до $325 \mu \mathrm{m}$ (рис. 2). Внутри больших окружностей иногда наблюдаются более мелкие круговые элементы. Микротвердость внутри круговых образований выше твердости материала вне этих областей $(\mathrm{HV}=2.62 \mathrm{GPa})$ на $\sim 25 \%$ и в среднем составляет $\mathrm{HV} \approx 3.14 \mathrm{GPa}$. Таким образом, можно предполагать, что на первом этапе проникания, когда скоростные параметры ударника еще достаточно велики, материал мишени не успевает осуществлять диссипацию механической энергии ударника за счет коллективного движения и размножения дислокаций. Поэтому
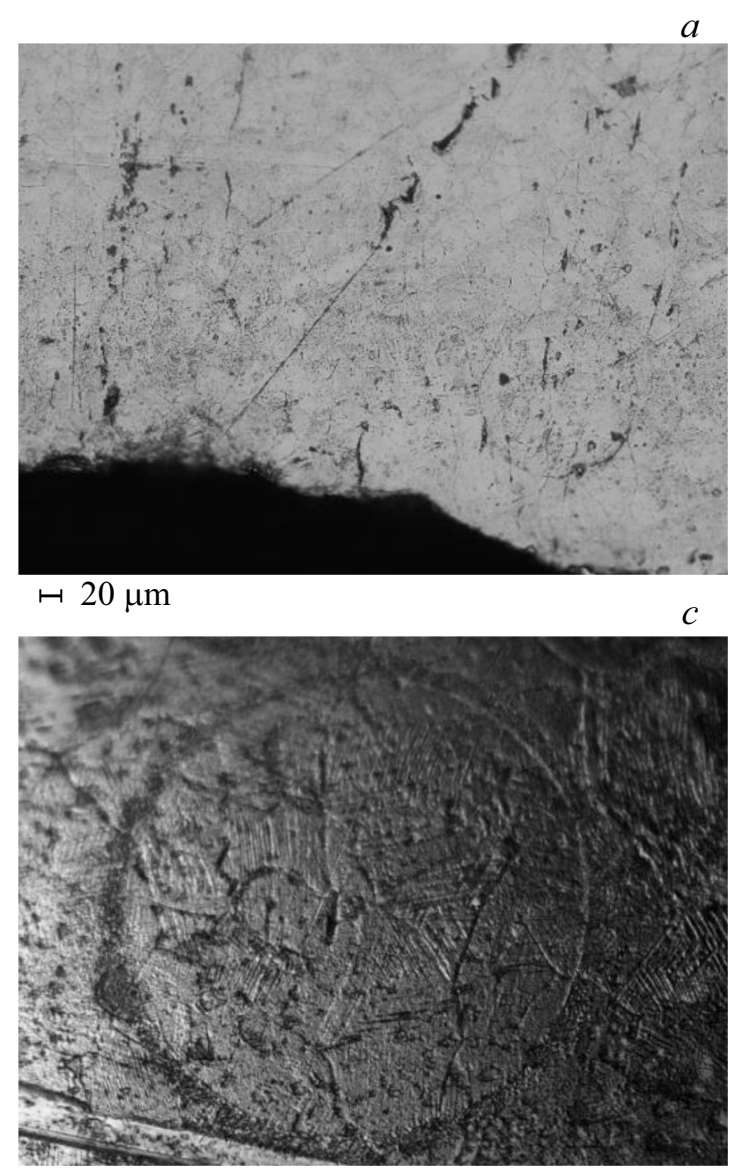

$c$
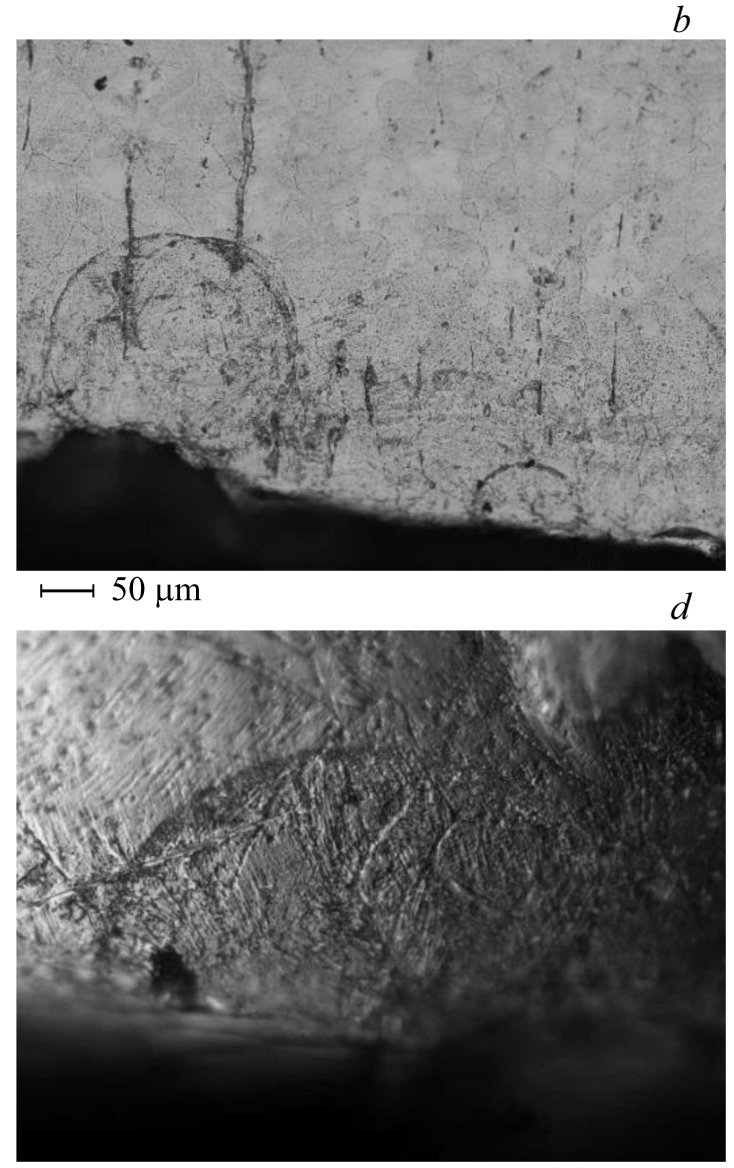

$\longmapsto 10 \mu \mathrm{m}$

Рис. 2. Области ротационной деформации $\times 200(a, b), \times 1000(c, d$ C-DIC). 


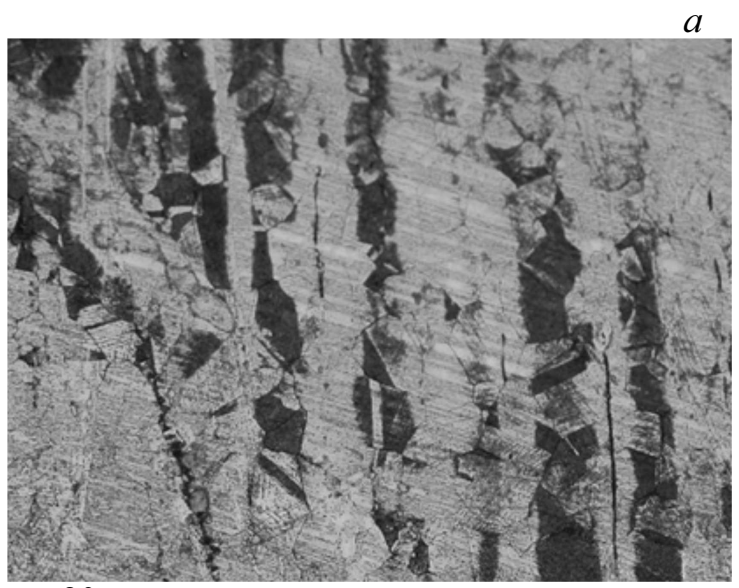

$\mapsto 20 \mu \mathrm{m}$

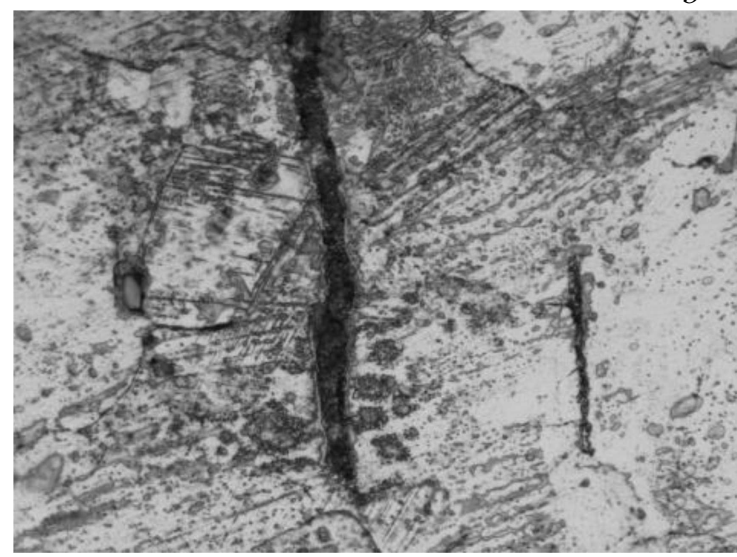

н $5 \mu \mathrm{m}$

Рис. 3. Двойниковые полосы $(a)-\times 200$, переходящие в микротрещины $(b)-\times 1000$.

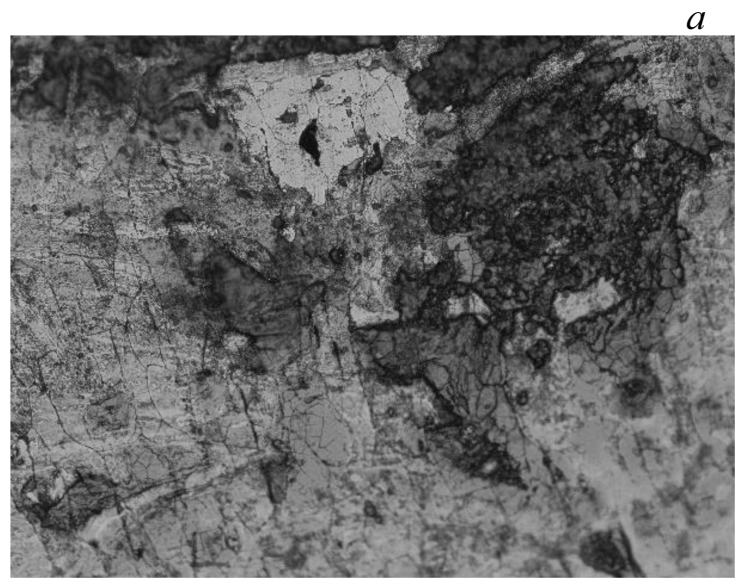

$50 \mu \mathrm{m}$

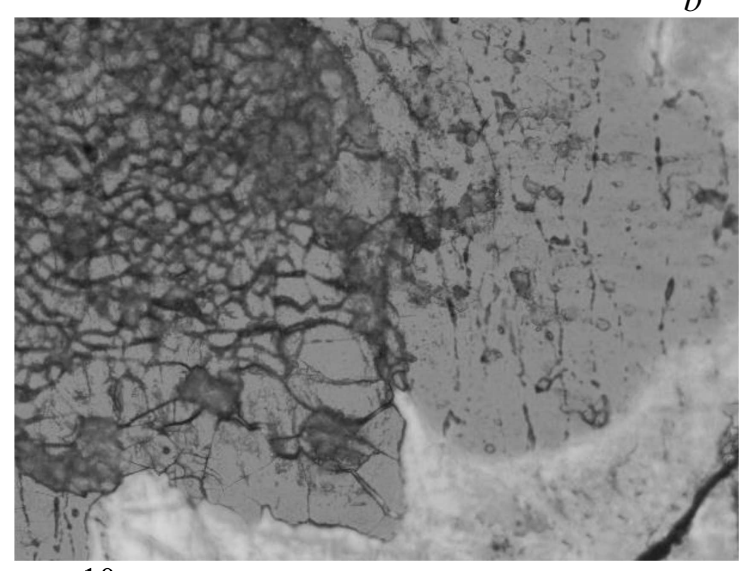

$\mapsto 10 \mu \mathrm{m}$

Рис. 4. Оплавление мишени (на расстоянии $4000 \mu$ т от поверхности нагружения) $\times 200(a), \times 1000(b)$.

для поддержания скорости диссипации на необходимом уровне включаются дополнительные ротационные моды пластической деформации [6].

Ранее такие области ротационной деформации были обнаружены во встречных волнах разгрузки [7] в меди, сталях, титановом сплаве, сплавах с памятью формы $\mathrm{Cu}-\mathrm{Mn}$. Указанные области в [7] также имели округлую форму диска, внутри которого зерна были измельчены до микрокристаллического (нанокристаллического) состояния, что указывало на динамическую рекристаллизацию материала. В нашем случае динамическая рекристаллизация нержавеющей стали 08Х18Н10Т внутри зон ротационной деформации отсутствовала.

Также в первой зоне мишени на расстоянии $3.0-3.5 \mathrm{~mm}$ от нагружаемой поверхности и $0.2-0.7 \mathrm{~mm}$ от края каверны обнаружены полосы (рис. 3), состоящие из двойников, образовавшихся в процессе нагружения материала ударной волной, сформировавшейся при проникании ударника. Микротвердость внутри полос в среднем составляет $3.29 \mathrm{GPa}$, что выше микротвердости вне этих полос на $\sim 25 \%$.

Кроме того, в первой зоне (рис. 4) на расстоянии $4 \mathrm{~mm}$ от фронтальной поверхности обнаружены области оплавления металла с измельченной равноосной зеренной структурой (средний размер зерен 5-10 $\mu \mathrm{m}$, наблюдались также зерна меньшего и большего размера). Таким образом, доля энергии, идущая на пластическое деформирование, была настолько большая, что ее было вполне достаточно для частичного оплавления локальных областей мишени.

Приблизительно на 1/3 толщины от тыльной поверхности мишени, что соответствует стационарному этапу проникания, на расстоянии от 2 до $3 \mathrm{~mm}$ на берегах отверстия присутствуют трещины протяженностью до $3 \mathrm{~mm}$, ориентированные относительно направления действия ударника в разные стороны на угол 45 градусов. Такие особенности позволяют полагать, что в условиях динамического воздействия в мишенях 
$a$
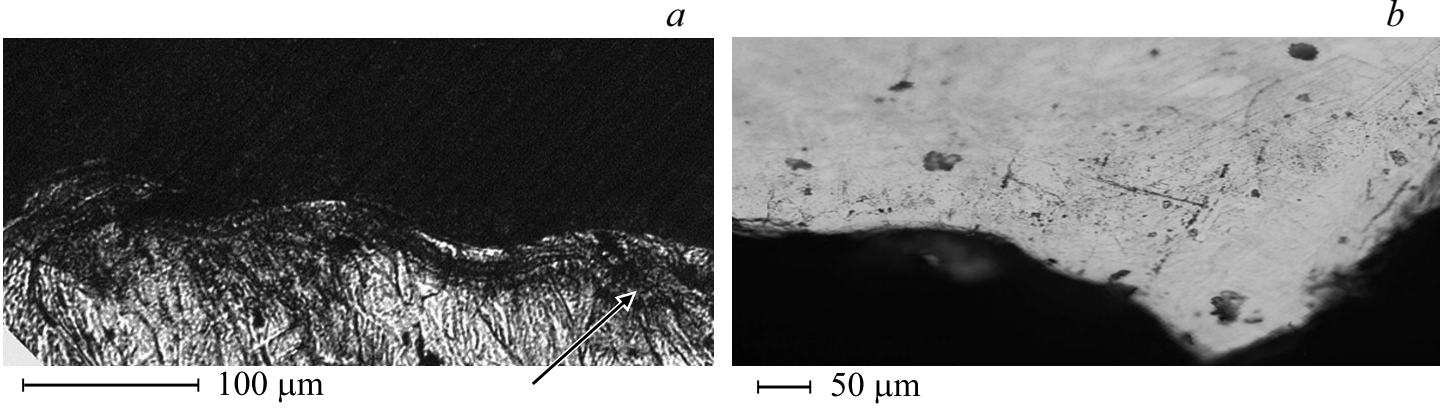

Рис. 5. Волнообразный рельеф на поверхности мишени: $a$ ) травленый шлиф, $b$ ) нетравленый шлиф, стрелкой указана ПАС.
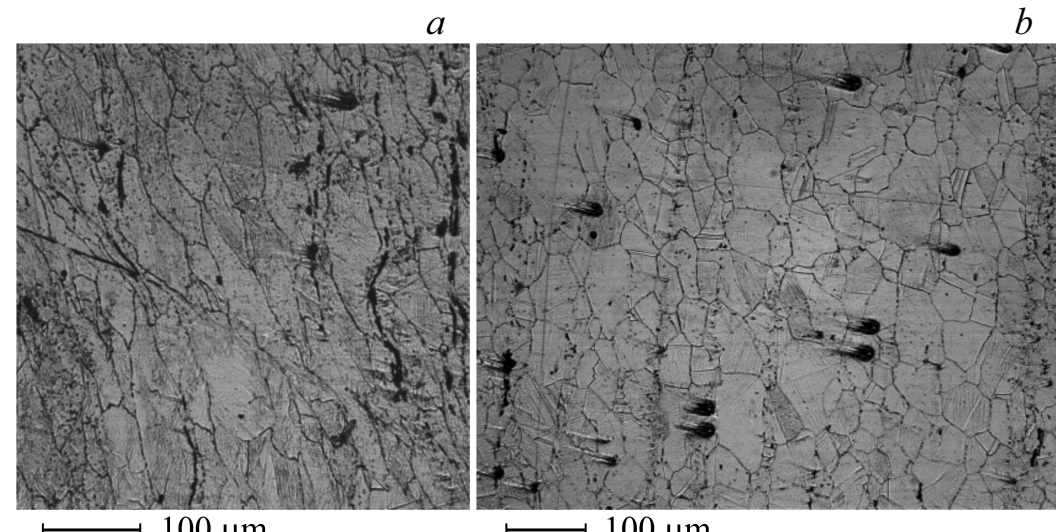

$b$

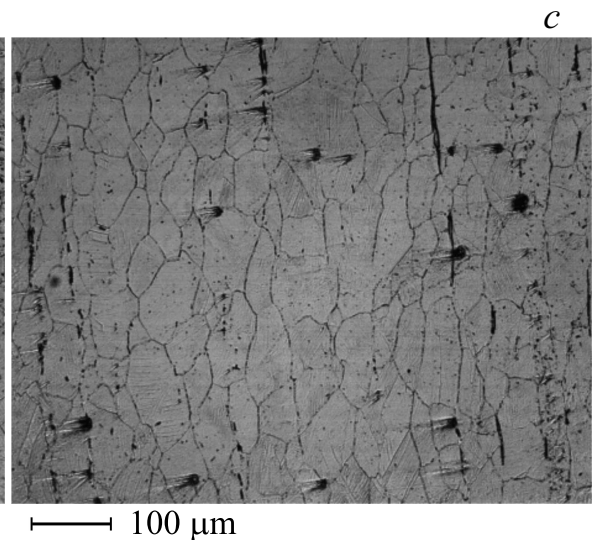

Рис. 6. Локализованные сдвиги и волнообразные следы пластической деформации $(a)$, дробление колоний $\delta$-феррита $(b)$ и следы укрупнения зерен $(c)$.

реализовалось сжатие вдоль одной оси, которое трансформировалось в объемное разноименное деформированное состояние. Вначале тензор деформации (g) характеризовался только одной диагональной компонентой $\mathrm{e}_{3}<0$, к которой в дальнейшем добавились диагональные компоненты в соотношении: $\mathrm{e}_{1}>0 ; \mathrm{e}_{2}>0$ и е $\mathrm{e}_{3}<0$, в результате чего и образовались указанные трещины. Можно также предположить, что возникновение трещин сопровождалось интерференционными эффектами образующихся при ударе волн, на что косвенно указывает близкая по величине периодичность раскрытых трещин и волнообразный профиль рельефа на поверхностях отверстия (рис. 5).

Второй этап процесса проникания ударника характеризуется активацией пластического течения и локализацией сдвигов в форме полос адиабатического сдвига (ПАС) (рис. 5,6), а также мезотрещинами отрыва длиной до $150 \mu \mathrm{m}$, при этом ПАС также повторяют волнообразный профиль рельефа поверхности каверны. Как известно [8], локализация деформации при высокоскоростном нагружении и образование полос адиабатического сдвига в общем случае связано с нестабильностью пластического течения, возникающей в результате эффекта термического разупрочнения при адиабатической или почти адиабатической пластической деформации. В случае квазистатических условий образование полос адиабатического сдвига характерно для высокопрочных материалов и, кроме того, для адиабатических условий доля работы сдвиговой пластической деформации во всех материалах и для всех условий нагружения не сохраняется в виде дефектов структуры [8].

Для динамического нагружения образование ПАС, вероятно, возможно. Это связано с тем, что в этом случае реализация образования ПАС возможна через механизм „задержки волны““ [8], который заключается в следующем. При адиабатическом сдвиге, как для квазистатического, так и для высокоскоростного нагружения, должно быть выполнено условие

$$
\partial \tau / \partial \gamma=0,
$$

где $\tau-$ сдвиговое напряжение пластического течения, $\gamma$ - пластическая деформация сдвига.

Для динамического нагружения скорость распространения волны пластического сдвига $V_{p}^{s}$ определяется выражением

$$
V_{p}^{s}=\sqrt{\frac{1}{\rho} \frac{d \tau}{d \gamma}} .
$$

В случае, когда степень деформационного упрочнения, определяемая соотношением (1), достигает нулевого значения, пластическая волна сдвига перестает распространяться и происходит локализация деформации. 

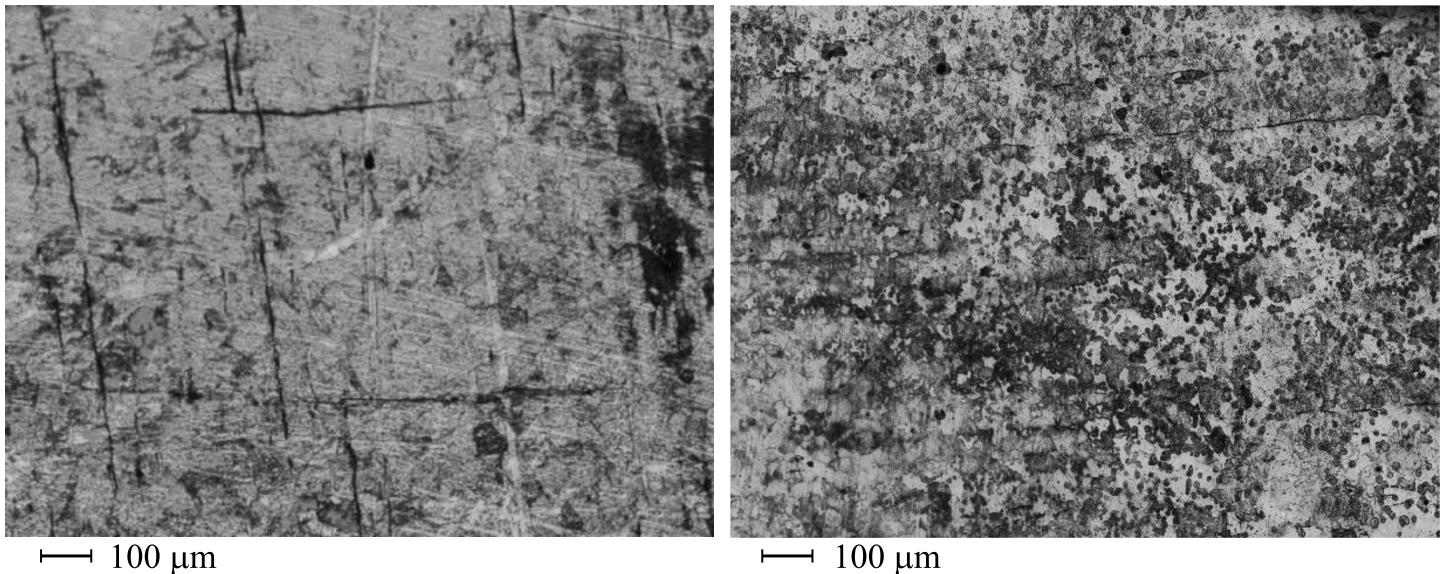

Рис. 7. Откольные и сдвиговые трещины в стали $\times 100$.

В нашем случае сталь 08Х18Н10Т имеет невысокие значения прочности даже при скорости деформации $\dot{\varepsilon}=2 \cdot 10^{3} \mathrm{~s}^{-1}$ [9]. Так, динамический предел текучести $\sigma_{\mathrm{sd}}=570 \mathrm{MPa}$, динамический предел прочности $\sigma_{\mathrm{bd}}=950 \mathrm{MPa}$, при этом динамическое относительное удлинение $\delta_{\mathrm{d}}=55 \%$, динамическое сужение $\psi_{\mathrm{d}}=66.5 \%$, т.е. мы имеем дело с высокопластичной сталью средней прочности.

Локальное тепловыделение, достаточно на этом этапе проникания для процессов рекристаллизации. Рекристаллизация проявляется в виде укрупнения зерен. Внутри зеренной структуры, как и в первой зоне, наблюдаются признаки ротационной (волнообразной) пластической деформации. Все признаки перечисленных эффектов представлены на рис. 6.

В третьей зоне мишени, связанной с интерференцией волн нагрузки и разгрузки, наблюдались два типа трещин: параллельных тыльной поверхности и перпендикулярных им трещин сдвига (рис. 7). Вторые обусловлены дисперсией скорости частиц материала мишени при нагружении ударными волнами в процессе проникания высокоскоростных ударников [10].

И, наконец, несмотря на то, что в процессе пластического деформирования металлов и сплавов могут одновременно реализовываться несколько механизмов течения, конкретный вклад которых определяется типом кристаллической решетки, химическим и фазовым составом, дефектной структурой металла [11], в нашем случае такое утверждение нельзя считать бесспорным.

\section{4. Заключение}

В целом по результатам исследований можно констатировать, что при пробитии мишени из стали 08X18Н10Т трансформации деформированного состояния происходят вследствие диссипации механической энергии в последовательности: скольжение дислокаций, ротационные моды, локализованные адиабатические сдвиги, полосы фрагментированного состояния и динамической рекристаллизации, локальная динамическая полигонизация и рекристаллизация. Структурные изменения слабо зависят от исходной структуры металла и реализуются с участием интерференционных (волновых) эффектов рассеяния ударной волны.

\section{Финансирование работы}

Работа выполнена при финансовой поддержке гранта РНФ 17-11-01053

\section{Конфликт интересов}

Авторы заявляют, что у них нет конфликта интересов.

\section{Список литературы}

[1] В.И. Колпаков, Г.Г. Савенков, К.А. Рудометкин, А.Ю. Григорьев. ЖТФ 86, 8, 21 (2016).

[2] В.Н. Аптуков. Проблемы прочности 2, 60 (1990).

[3] Г.Г. Савенков, Т.А. Хантулева. ЖТФ 84, 1, 38 (2014).

[4] В.В. Башуров, Г.В. Бебенин, Г.В. Белов, Ю.Н. Бухарев. В сб.: Прикладные задачи высокоскоростного удара. ФГУП „РФЯЦ-ВНИИЭФ“, Саров (2011). С. 197.

[5] Б.К. Барахтин, А.А. Прус, Г.Г. Савенков. Прикладная механика и техническая физика 5, 155 (1989).

[6] В.В. Рыбин. Большие пластические деформации и разрушение металлов. Металлургия, М. (1986) 224 с.

[7] S. Atroshenko. Metals dynamic recrystallization up to nanocrystalline size induced shock loading. AIP Conf. Proc. 1748, 030005 (2016).

[8] Г.Б. Ольсон, Дж.Ф. Мескол, М. Азрин. В сб: Ударные волны и явления высокоскоростной деформации металлов / Под ред. М.А. Мейерса и Л.Е. Мурра. Металлургия, М. (1984). C. 67.

[9] Г.Г. Савенков, А.В. Кузнецов. Вест. Тамбов. ун-та. Сер. Естеств. и технич. науки 21, 760 (2016).

[10] Г.Г. Савенков, Ю.И. Мещеряков, Б.К. Барахтин. ЖТФ 80, 10, 136 (2010).

[11] Б.А. Зимин, В.Е. Свентицкая, И.В. Смирнов, Ю.В. Судьенков. ФТТ 60, 754 (2018).

Редактор Т.Н. Василевская 